\title{
On "A Method of Measuring the Volume of the Circulating Blood in the Lungs and the Minute Volume by Means of Sodium Para-aminohippurate" (A Correction)
}

By

\author{
Takashi Yamaguchi and Yasuhiko Hino \\ (山口隆) (日野泰賢) \\ From the Medical Clinic of Prof. $F$. $\mathcal{N} a k a z a w a$, \\ Tohoku University, Sendai
}

(Received for publication, August 16, 1956)

In the previous report" "A Method of Measuring the Volume of the Circulating Blood in the Lungs and the Minute Volume by Means of Sodium Para-aminohippurate", we calculated the minute volume of plasma (M) and the volume of the circulating plasma in the lungs $(Q)$ by using the value of renal plasma flow (v). But, when the excretion rate of $\mathrm{PAH}$ in the kidneys is $p$, we can get $M$ and $Q$ by using the value of $p v$, and it is not necessary to get $\mathrm{v}$.

In order to get the formula, with which $\mathrm{pv}$ is calculated, $0.88 \mathrm{v}$ in the previous report ${ }^{1}$ must be substituted by $\mathrm{pv}$, and consequently the following formula is obtained instead of that, with which $\mathrm{v}$ is calculated.

$$
\mathrm{Pv}=\frac{\frac{2.303}{\mathrm{t}_{1}} \log _{10} \frac{\mathrm{C}_{0}}{\mathrm{C}_{1}}}{\frac{\mathrm{C}_{n}-\mathrm{C}_{1}}{x_{1}}}
$$

The values of $\mathrm{pv}$ can be got by multiplying $\mathrm{v}$ in the table by 0.88 .

To get the formula, with which $M$ is calculated, $0.88 \mathrm{v}$ and $0.12 \mathrm{v}$ must be substituted by $\mathrm{pv}$ and $(1-\mathrm{p}) \mathrm{v}$ respectively in the previous report. $\left.{ }^{1}\right)$

And to get the one, with which $Q$ is calculated, $0.88 \mathrm{v}$ and $0.12 \mathrm{v}$ must be similarly substituted by $\mathrm{pv}$ and $(1-\mathrm{p}) \mathrm{v}$ respectively, and the same formula as described in the previous report ${ }^{11}$ can be derived.

Thus, the values of $M$ and $Q$ are the same as was shown in the table, and it is clear, that our method of measuring the volume of the circulating blood in the lungs and the minute volume can be applied generally, whatever the excretion rate of $\mathrm{PAH}$ in the kidneys is.

\section{References}

1) Yamaguchi \& Hino, Tohoku J. Exp. Med., 1955, 62, 243. 